\title{
Challenges of a Project-based Learning towards Requirement Engineering
}

\author{
Nor Azliana Akmal Jamaludin \\ Faculty of Computer Science and Information \\ System \\ Universiti Teknologi Malaysia (UTM) \\ Skudai, 81310 Johor \\ MALAYSIA
}

\begin{abstract}
Higher Learning Education (HLE) fails to deliver undergraduates with employability skills that expert in Requirement Engineering. The objective of this research is to identify challenges in the current practice of teaching Software Engineering at the undergraduate level in Requirement Engineering. To that reason, the Project-Based Learning (PjBL) proposed as well as a mechanism for educators in their delivery to assist students in enhancing their skill. The skills enhanced from the elicitation process until the management of requirement which students can easily apply in their employability skills. Future work will discuss on the analysis of the weaknesses in the current Requirement Engineering practices.
\end{abstract}

\section{General Terms}

Requirement Engineering, Project-based Learning.

\section{Keywords}

Higher Learning Education, Software Engineering Education, Requirement Engineering, Project-Based Learning, ProblemBased Learning, Product-Based Learning, Employability skill.

\section{INTRODUCTION}

In the Al-Quran, Surah Al-A'laq stated that Allah S.W.T. teach human being through the writing which transcended from the angel Jibrail to the Prophet Muhammad S.A.W at the Hira' in a cave as the first sentence of Al-Quran. This first event showed us that a human being should learn, memorize and apply all the study as well as knowledge.

A sentence of Surah Al-Alaq, "Read (Iqra') from the name of Allah". The sentence states that Allah S.W.T teaches everything to the human that a human does not know [1] from beginning and apply by prophet Muhammad S.A.W. Prophet Muhammad S.A.W chosen by Allah S.W.T. His task was to inform and spread the taught to all mankind from that moment onwards. It was difficult to teach them at first, but through creative mechanism learning and good thinking habits, human being learned and accepted it easily until now.

It is because the Al-Quran contains about everything including education, life, science and others. It can be closely related with Software Engineering education in general. Requirement Engineering education particularly is propose to use ProjectBased Learning as a mechanism for educators in their delivery to assist the student in enhancing their employability skill.

\section{EMPLOYABILITY SKILL}

The sustainable world-class performance will not occur if there is a misalignment between university programmes objectives and actual market requirements. In addition, effective faculty wide coordination in relation to market driven initiatives is essential for ensuring the effective use of company resources [35]. Employers now focus on adaptation,

\author{
Shamsul Sahibuddin \\ Advanced Informatics School(AIS), UTM \\ International Campus \\ Universiti Teknologi Malaysia (UTM) \\ Jalan Semarak, 54100 Kuala Lumpur \\ MALAYSIA
}

cost reduction, increased productivity, new markets, products and services.

Table 1. Common elements of various listings of generic skills [14].

\begin{tabular}{|l|l|}
\hline Generic Skill & Example \\
\hline $\begin{array}{l}\text { Basic/fundament } \\
\text { al skills }\end{array}$ & $\begin{array}{l}\text { literacy, using numbers, using } \\
\text { technology, knowledge and skills }\end{array}$ \\
\hline $\begin{array}{l}\text { People-related } \\
\text { skills }\end{array}$ & $\begin{array}{l}\text { communication, interpersonal, } \\
\text { teamwork, customer-service skills }\end{array}$ \\
\hline $\begin{array}{l}\text { Conceptual/thin } \\
\text { king skills }\end{array}$ & $\begin{array}{l}\text { collecting and organizing information, } \\
\text { problem-solving, planning and } \\
\text { organizing, learning-to-learn skills, } \\
\text { thinking innovatively and creatively, } \\
\text { systems thinking }\end{array}$ \\
\hline $\begin{array}{l}\text { Personal skills } \\
\text { and attributes }\end{array}$ & $\begin{array}{l}\text { responsible, resourceful, flexible, able } \\
\text { to manage own time, having a self- } \\
\text { esteem }\end{array}$ \\
\hline $\begin{array}{l}\text { Skills related to } \\
\text { the business } \\
\text { world }\end{array}$ & innovation skills, enterprise skills \\
\hline $\begin{array}{l}\text { Skills related to } \\
\text { the community }\end{array}$ & civic or citizenship \\
\hline
\end{tabular}

Employees need to demonstrate teamwork, problem-solving and the capacity to deal with nonroutine processes. They should also be able to make decisions, take responsibility and communicate effectively. Proficiency in the broad range of generic skills has become the main requirement for the modern worker. The skills required not only to gain employment, but also to progress within an enterprise so that it can achieve one's potential and contribute successfully to enterprise strategic directions. Employability skills are also sometimes referred to as generic skills and capabilities or key competencies [14] as shown in Table 1.

Seventy-seven per cent employers want employees that have team-working skills. Another seventy-one per cent employers seek employees with problem-solving skills. However, employers then also expect these candidates to hold a more sophisticated and often work-specific set of skills. Eighty-six per cent of employers said that personal presentation should be fully developed, suggesting they want to employ people who appear to be professional [30]. 


\subsection{The Importance of Fundamental Skills in Successful Project}

In the summary of the NATO Science Committee report [30], the problems observed in 1968 are striking similar to the current problems to achieve sufficient reliability in the data systems. The problems integrated into the central activities of modern society, difficulties of meeting schedules and specifications on large software projects or education of software (or data systems) engineers.

Nowadays, society is increasingly dependent on software. Software failures can cause or contribute to serious accidents that result in death, injury, significant environmental damage, or financial loss. Such accidents have already occurred, and without intervention, the increasingly pervasive use of software - especially in arenas such as transportation, health care, and the broader infrastructure - may make them more frequent and more serious [24]. As observed by Hoare (2006), "The real value of tests is not that they detect bugs in the code but that they detect inadequacies in the methods, concentration, and skills of those who design and produce the code."

Thus, it is likely that the nature of products and processes would also evolve toward the complementarities of skills in such areas as culture-matching and localization [12]. Some key culture-matching dimensions provided in [20]: power distance, individualism / collectivism, masculinity / femininity, uncertainty avoidance, and long-term time orientation. These often explain low software product and process adoption rates across cultures.

\section{REQUIREMENT ENGINEERING EDUCATION AS A KICK-START FOR THE STUDENT IN DEVELOPING THEIR SKILL}

Most literatures agree that skill is a crucial part for Software Engineering student if the student wants to be employed by the industry. The students' skill should be developed from the beginning of Software Engineering phase. It is because if they failed to understand from the early phase, so it will be hard for them to understand the next phase. Furthermore, the successful of the end product depends on stakeholder's satisfaction. It can be seeing from a product that match and satisfy user requirement. Software Engineering has five main phases. It consists of software requirement, design, development, testing and maintenance.

Requirement Engineering (RE) is a vital part in software requirement $[8,10]$. RE process involves elicitation, analysis, verification and validation, and management. RE differentiated by two parts. Firstly, software development and secondly, management [32]. These two parts widely used in CMMI (Capability Maturity Model Integration) to recognize works in matured organization. CMMI is a popular tool that can identify and certify organization who achieved a standard in their organization based on their matured process and services. If RE not captured a right problem or requirement from user, so the solution for software artifact will not be accurate.

\section{REQUIREMENT CHALLENGES}

ENGINEERING

Requirement Engineering (RE) issues [10, 11] are still unresolved because of the rapid changes in technologies. Daily usage of the system and software becomes significance for everyone in the world. Many issues that not raised previously will arise in the future. It becomes a challenge [7] to RE community to improve the solution. It cannot be waited until it happen because "prevention is better rather than cure". The common problems with unsuccessful project defined as late, over budget, and/or not fulfill the required features and functions. It also defined as cancelled (before it can be completed or delivered) and never used [13]. The challenges in RE now focus on system that relates with scale, cyberphysical system, self-adaptive system, security [25] and globalization [11].

The educator has the biggest responsibility to teach the student on how to manage and develop quality software based on user expectation before they go to work in a real environment. The educator faces the problem on how to simplify RE learning process. The educator needs to make student understand as a whole about the significance of RE in a real project that consist of soft and hard skill [4] on how they can successfully capture requirement from stakeholders, analyze and model. The data that been captured and verify and then validate the requirement. Additionally, the crucial part is deliverable. It used to control change management. It is because the changes (minor or major) will effect to the overall project.

Another issue, the faculty needs to organize their infrastructure with minimal requirement that can support the learning environment in RE [37]. Higher Learning Education should conduct a survey of technology that adapted from the industry within five-year projections to avoid significant differences in technology used. The infrastructure is beneficial because it can help students understand the concept, attract students to study and enhance their skills.

\section{TRADITIONAL METHOD}

There are lots of traditional methods that using face-to-face learning. Somehow, there are weaknesses compared to benefit arise in the approaches. Computer-mediated peer interaction introduced and enhanced with e-learning. The e-learning is to encounter the problem for the student who did a problem in distance to come to the place for learns. At the same time, the students face a difficulty of managing time and schedule to fit with the lecturer schedule.

Technological tool would appear to be more successful in forging links between strangers, creating a bridge which might have maintained in personal face-to face communication situations in learning and professional settings[33]. The result shows in that paper is strictly dependent on age, motivation, class size, cultural background and study domain as significant variables.

The benefit in using computer mediated peer interaction can improve their English expression and use. In addition, it can also achieve quality learning outcome by developing skills of collaborative learning and multicultural communication [5]. To that reason, the uniqueness of this study is to focus on Project-based Learning approach. This study proposed the Project-based Learning technique in Experiential learning [39] to resolve the said current problem,

\section{EXPERIENTIAL LEARNING}

Compared to activities in the traditional method (face-to-face that required lecturing and listening only), as said by members of Association for Business Simulation and Experiential Learning (ABSEL) dedicated to the proposition that students can learn from experience. Most people remain to the notion of "trial and error" learning. Arab proverb said, "Knowledge 
without practice seems like a tree without fruit". Confucius expressed their conviction that experiential learning is effective: "I hear and I forget, I see and I remember, and I do and I understand". Others have cited Sophocles quote from 400 B.C., "One must learn by doing the thing, for though you think you know it-you have no certainty, until you try." Or, one could quote George Santayana, "The great difficulty of education is to get experience out of ideas." It is hard to argue that experience will not lead to learning under the right conditions. However, it argued that the resultant learning can be in error unless care taken to assure that those conditions occur [39].

Experiential method [26] refers to the terms of evaluation or what has changed or improved to a result. This literature reported that experiential method focus on all variables which scholars have presumed to be influenced that include cognitive learning, behavioral change, skill development, and attitude change. Bloom's taxonomies are appropriate means for categorizing outcomes. Attitude change includes attitudes toward the course or program. These are assessments or features of experiential exercises or programs, rather than assessments of the exercise or the program itself. Examples of features include exercise duration or complexity of decisionmaking required in an exercise.

\section{PROJECT-BASED LEARNING (PJBL)}

However, look beyond them to the fundamental concepts had not changed significantly since they emerged when the field took shape some thirty (30) years ago. As in hardware design, the technology evolves, but the concepts remain [9]. Students usually learn best by physically doing something. Students of course will be more interested to come to school if they think that education is fun, beneficial or the future and not as a burden [2].

The proposed Project-Based Learning is a superset for Individual \& Collaborative Problem Solving [16, 17, 19, 41] Problem-Based Learning [3, 13, 16, 19, 25, 34] and ProductBased Learning [27, 34]. In contrast, all of them are subset to Project-Based Learning and the subsets intersect among others. The PjBL [14] consists of conceptual thinking and interpersonal teamwork skills.

If the PjBL want to be implemented successfully for Software Engineering undergraduate students, Then, suitable tools, the expertise people of $\mathrm{PjBL}$ need to come up with a guideline that refers on tertiary culture. By the time the need identified, the courses developed, and the students trained, the new technology has changed. The succeed education should facilitate lifelong learning, equip students with the skills and easily adapt the changes. The information of PjBL practices (such as productiveness, effectiveness in comparison to other methods and framework) is still lacking [40]. The educators face many difficulties in choosing the most suitable project type for each level of program (diploma, degree or master level). The educator should form a project team and identify their roles $[6,37]$.

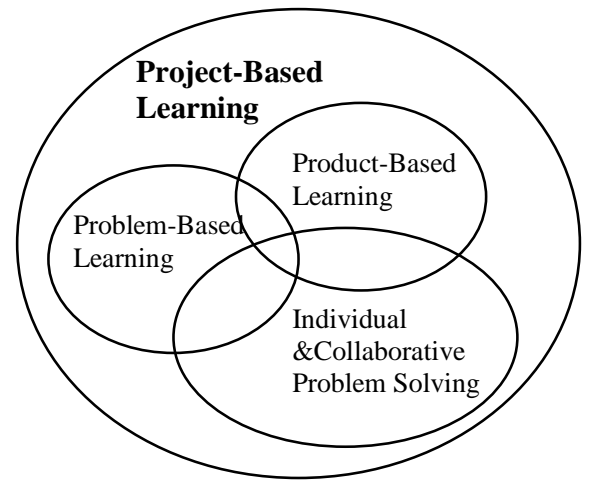

Figure 1: Problem-Based Learning, Individual \& Collaborative Problem Solving and Product-Based

Learning are a subset to Project-Based Learning [28].

In order to initiate the Project-Based Learning (PjBL) for educators and students, Problem-Based Learning (PBL) form the basic step for the student to start the project. The goals of PBL include helping students develop flexible knowledge, effective problem-solving skills, Self-Directed Learning (SDL) skills, effective collaboration skills, and intrinsic motivation [22]. The number of technophobia is decreasing when PBL concept replace the traditional teaching process introduced in IT education.

The activities in PBL require students to solve the problem that authentically ill structured. The preparation of the guideline expected to help student solve the problems. The authentic and/or performance-based should be an assessment. The methods involved the participants, procedures, measurement, findings and discussion.

The PBL motivates students to become an active learner and work with real problems to encourage their future career [36]. The outcome [9] shows that the added-value of PBL helps in improving the learning process of the students. The PBL activities would make the subject matter more attractive to the students and retain knowledge for a longer period than if their learning had used traditional format.

As an extension, to the Problem-Based Learning, the solution to an open-ended problem which requires the development of a real-world product introduces the Product-Based Learning. This approach provides further motivation by establishing the goal of satisfying a real user base. The students are not only responsible for their own learning and the success of the team, but they must also take responsibility for a quality product to be used by end users. This allows the educator to be aware of student thinking, close connection with learning environment and development processes. Not only do the students benefit from more helpful and relevant guidance, but the educator benefits by experiencing the same interaction and motivation that drives the students [34].

\section{CONCLUSION}

It can be concluded that the human factor or attitude of educators and students directly involved to ensure the process of Project-Based Learning (PjBL) is successful. Then only the student will see, understand and confident to apply the knowledge. It will benefit the students before enter working environment after graduation. Higher Learning Education needs to understand that a suitable learning technique will represent a quality student which can have plenty of skill. In addition, if the university think about the long-term benefit in terms of sending the educator for training to increase their knowledge in their teaching method and delivery mechanism. Educators and students act as a prominent role when 
implementing new learning method. Additionally, proper guideline is still lacking on how to implement the industry perspective into Software Engineering education. Besides, the significance of research that published and discussed on Software Engineering education in seminar, conference, proceedings and others should be included in structuring new curriculum or restructuring curriculum. The time consuming might have considered when implementing the learning method and reschedule the planning to review the existing curriculum at the faculty frequently. Future work will discuss an analysis of the weaknesses in current Requirement Engineering practices by getting a feedback from ICT practioner. The quantitative method will be using to measure the weaknesses of current problem in Higher Learning Education using Rasch Measurement Model.

\section{REFERENCES}

[1] Al-Quran. Al-A'laq. Kuala Lumpur: Darulfikir. 1420H.

[2] Ariffin, R., \& Ismail, H. N. (2007). Konsep Keadilan dalam Teori Kecerdasan Pelbagai Menurut Perspektif Islam. Pendidikan Psikologi.

[3] Azer, S. A. (2009). Interactions Between Students and Tutor in Problem-Based Learning: The Significance of Deep Learning. The Kaohsiung Journal of Medical Sciences , 25 (5), 240-249.

[4] Bagert, D. J., Port, D. N., \& Saideian, H. 2008. Software Engineering Education, Training and Research: The Legacy of Nancy Mead. IEEE, Vol. 1, pp. 238-243.

[5] Bakar, M. S., \& Shaikh Ab Rahman, S. N., 2005. A Kick Start in Implementation of PBL in Computer Programming. Proceedings of the 2005 Regional Conference on Engineering Education.

[6] Bernhart, M., Grechenig, T., Hetzl, J., and Zuser, W., 2006. Dimensions of Software Engineering Course Design. Proceedings of the 28th international conference on Software Engineering Shanghai, China, pp. 667-672.

[7] Boehm, B. 2006. A View of 20th and 21st Century Software Engineering. International Conference on Software Engineering (ICSE), Shangai, China. Proceedings New York, ACM Press, Vol. 28, pp. 12-29.

[8] Broy, M. Requirement Engineering as a Key Holistic Software Quality. Verlag Berlin Heidelberg: Springer. 2006.

[9] Carlisie, C., \& Ibbotson, T. (2005). Introducing ProblemBased Learning into Research Methods Teaching: Student and Facilitator Evaluation. IEEE, 527-541.

[10] Cheng, B. H., \& Atlee, J. M. 2007. Research Directions in Requirement Engineering. Future of Software Engineering, 2007. FOSE '07 In Future of Software Engineering, 2007. pp. 285-303.

[11] Cheng, B. H., \& Atlee, J. M. 2009. Current and Future Research Directions in Requirements Engineering. Design Requirements Engineering: A Ten-Year Perspective, pp. 11-43.

[12] Crawford, D.. Editorial Pointers. Comm. ACM . 2001

[13] Crear, J.. CHAOS Summary 2009. The Standish Group International Inc. Boston, Massachusetts: Standish Group's. 2009

[14] Curtin, P. 2004. Generic skills in vocational education and training. Australian Chamber of Commerce and Industry \& Business Council of Australia, Department of Education, Science and Training. Canberra, Autralia: National Centre for Vocational Education Research Ltd.

[15] Edelson, D. C., Gordin, D.N., \& Pea, R. D. 1999. Addressing the challenges of inquiry-based learning through technology and curriculum design. Journal of the Learning Sciences, Vol. 8, No. 3, pp. 391-450.
[16] Ellis, A. 2001. Student-Centred Collaborative Learning via Face-to-Face and Assynchronous Online Communication: What's the Difference? In G. Kennedy, M. Keppell, C. McNaught \& T. Petrovic (Eds.), Meeting at the Crossroads. Proceedings of the 18th Annual Conference of the Australian Society for the Computers in Learning in Tertiary Education. Melbourne: Biomedical Multimedia Unit, The University of Melbourne. pp. 169-178.

[17] Frezza, S., \& Cannell, J. 2009. Product-Based Learning in Software Engineering Education. Frontiers in Education Conference, FIE '09. 39th IEEE. 18-21 Oct. 2009. pp. 1-6.

[18] Good, J., Howland, K. and Thackray, L. 2008. Problembased learning spanning real and virtual worlds: a case study in Second Life. ALTJ. Research in Learning Technology, Vol. 16, No. 3, pp. 163-172.

[19] Guzdial, M., Turns, J., Rappin, N., \& Carlson, D. 1995. Collaborative support for learning in complex domains. Proceeding CSCL '95 The first international conference on Computer support for collaborative learning. pp. 157160.

[20] Harned, D., Lundquist, J. "What Transformation Means for the Defense Industry". The McKinsey Quarterly, November 3, 2003. pp. 57-63.

[21] Hashim, R., \& Mohd Din, M. A. 2008. Implementing Outcome-Based Education Using Project Based Learning at University of Malaya:An Evaluation. Proceedings Paris International Conference on Education, Economy and Society. pp. 51-59.

[22] Hmelo-Silver, C. E. 2004. Problem-Based Learning: What and How Do Students Learn? Plenum Publishing Corporation. Educational Psychology Review, September 2004. Vol. 16, No. 3.

[23] Hoare, C. A. 2006. How did Software get so Reliable without Proof? IEEE, pp. 1-17.

[24] Jackson, D., Thomas, M., and Millett, L.I. (eds.), Software for Dependable Systems: Sufficient Evidence?, The National Academies Press, Washington, DC, 2007.

[25] Khan, M. U. A. \& Zulkernine, M. On Selecting Appropriate Development Processes and Requirements Engineering Methods for Secure Software. 33rd Annual IEEE International Computer Software and Applications Conference, 2009. COMPSAC, Vol. 2, pp. 353-358.

[26] Kolb, A. Y. \& Kolb, D. A. 2007. Experiential learning theory: A dynamic, holistic approach to management learning, education and development.

[27] Leifer, L., 1995. Evaluating Product-Based-Learning Education. Vol. 28.

[28] Marshall, S. P. In the Service of Learning, Getting to the heart of Problem-based Learning. Summary Report, PBL Symposium. 2003

[29] Martin, R., F. Villeneuve-Smith, L. Marshall and E. McKenzie. 2008. Employability skills explored. Learning and Skills Network research report.

[30] Naur, P., \& Randell, B. Software Engineering Report of a conference sponsored by the NATO Science Committee Garmisch Germany 7th-11th October 1968. Germany: Scientific Affairs Division, NATO. 1969

[31] Nor Azliana Akmal, J., Shamsul, S., Kamaruzaman, J., Nur Hafizah, H. 2010. Development of a Project-Based Learning Approach in Requirement Engineering. International Journal of Computer Science and Information Security, IJCSIS, Vol. 8, No. 9, pp. 6.

[32] Phillips, M. 2009. CMMI and Process Improvement Themes. 
[33] Plantamura, P., Roselli, T., \& Rossano, V. (2004). Can a CSCL Environment Promote Effective Interaction? IEEE Computer Society.

[34] Ragan, E. D., Frezza, S., \& Cannell, J. 2009. ProductBased Learning in Software Engineering Education.

[35] Rashid, R. A. et al. 2008. Engineering Students Performance Evaluation of Generic Skills Measurement: ESPEGS Model. 5th WSEAS / IASME International Conference on Engineering Education .

[36] Rugarcia, A. et al. 2000. The Future of Engineering Education I. A vision for a New Century. Chem. Engr. Education, Vol. 34, No. 1, pp. 16-25.

[37] Rusu, et al. 2009. Academia-academia-Industry Collaborations on Software Engineering Projects Using Local-Remote Teams. ACM , pp. 301-305.
[38] Savery, J. R. 2006. Overview of Problem-based Learning: Definitions and Distinctions The Interdisciplinary Journal of Problem-based Learning. Vol. 1. No. 1.

[39] Smith, et al. (2009). Developments in Business Simulation and Experiential Learning. Association for Business Simulation and Experiential Learning.

[40] Thomas, J. 2000. 'A review of research on project-based learning', The Autodesk Foundation, San Rafael, California, https://www.bie.org/files/researchreviewPBL.pdf.

[41] Wolff, S. J. 2002. Design Features for Project-Based Learning. 